\title{
Reversible Control of DNA Binding with Cucurbit[8]uril-Induced Supramolecular 4,4'-Bipyridinium-Peptide Dimers
}

\author{
Paula Novo, Marcos D. García, Carlos Peinador,* and Elena Pazos* \\ Cite This: Bioconjugate Chem. 2021, 32, 507-511 \\ Read Online
}

ABSTRACT: Many cellular processes in living organisms are regulated by complex regulatory networks, built from noncovalent interactions between relatively few proteins that perform their functions by switching between homo- and heterooligomeric assemblies or mono- and bivalent states. Herein, we demonstrate that the conjugation of a 4,4'-bipyridinium scaffold to the basic region of the GCN4 bZip transcription factor can be exploited to control the dimerization of the conjugate by formation of a supramolecular complex with cucurbit[8] uril. Importantly, this supramolecular complex is able to specifically recognize its target dsDNA, and this binding can be reversibly switched by the application of external stimuli.

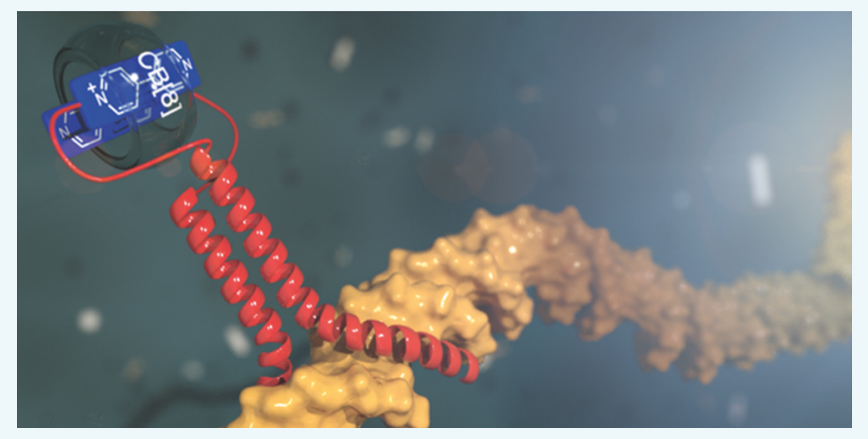

$\mathrm{P}$ roteins regulate many cellular processes in living organisms, ranging from cell cycle progression to cell motility or gene expression. Interestingly, in eukaryotic cells, such regulation is achieved by employing relatively few proteins. $^{1,2}$ Consequently, intricate regulatory networks are created through the combinatorial formation of diverse noncovalent protein-based complexes, frequently by switching between homo- and heterooligomeric assemblies or mono- and bivalent states. Inspired by these natural complexes, chemists have reported a variety of supramolecular systems that have demonstrated a considerable potential for the regulation of protein assemblies, modulating their function by means of host-guest interactions. $^{3-7}$

In the context of peptide dimerization, the macrocyclic host cucurbit $[8]$ uril $(\mathrm{CB}[8])$ has been reported to interact with phenylalanine-glycine-glycine (FGG) sequences, $^{8}$ and exploited to promote the association of functional peptide fragments. ${ }^{5,9,10}$ However, the use of this short peptide tag is limited to the dimerization of peptides through their $N$ terminus, due to the structural requirements of the $\mathrm{CB}[8]$ : $(\text { FGG })_{2}$ complex. ${ }^{8} \mathrm{CB}[8]$ has also been described to interact with middle-chain Phe and Trp residues to mediate peptide and protein dimerization. ${ }^{11,12}$ Nevertheless, to the best of our knowledge, the use of these homoternary complexes to drive the dimerization and control the biological activity of functional peptides has not been explored.

Prompted by these facts, the unique ability of $\mathrm{CB}[8]$ to form 1:2 hetero- or homodimeric inclusion complexes with a variety of guests, ${ }^{13-19}$ and our interest in the development of stimuli responsive host-guest and peptide-based systems, ${ }^{19-22}$ we envisaged that $C$-terminal oligomerization of peptides could be effectively mediated by $\mathrm{CB}[8]$ through the introduction of a $\mathrm{N}$ -

monoalkyl-4,4'-bipyridinium recognition motif $\left({ }_{\mathrm{p}} \mathbf{V}^{+}\right)$, which interacts with the macrocyclic host yielding $\mathrm{CB}[8]:\left({ }_{\mathrm{p}} \mathbf{V}^{+}\right)_{2}$ antiparallel homodimeric aggregates. ${ }^{23}$ Furthermore, the wellknown host-guest chemistry of the $\mathrm{CB}[8]$-bipyridinium pair allows for further implementation of dynamic behavior on the designed artificial peptides, in particular, on the prospective endorsement of redox or acid-base stimulation into those. ${ }^{19}$

We focused our attention on the Basic Leucine Zipper (bZip) transcription factor GCN4, which binds to its target dsDNA (ATF/CREB) as a leucine zipper-mediated homodimer of continuous $\alpha$-helices. ${ }^{24}$ The group of Kim demonstrated that a simplified peptide, in which the leucine zipper region at the $C$-terminus of the GCN4 DNA binding domain is replaced by a cysteine residue, is able to bind its target DNA sequence with high affinity after dimerization through a disulfide bond. ${ }^{25}$ Since then, other authors have exploited this strategy to incorporate new functionalities to the design of artificial GCN4 derivatives, ${ }^{3,26-30}$ exemplifying both its utility as simplified model for the study of protein homodimerization and of protein-DNA interactions. Herein, we demonstrate that the incorporation of a $4,4^{\prime}$-bipyridinium moiety at the $C$-terminus of the GCN4 basic region (GCN4br) affords a peptide derivative able to recognize ATF/CREB, upon formation of the supramolecular homodimer with $\mathrm{CB}[8]$.

Received: February 5, 2021

Revised: February 22, 2021

Published: March 8, 2021 
Furthermore, we show how the application of external stimuli can be effectively used to reversibly control the homodimer formation and its DNA binding.

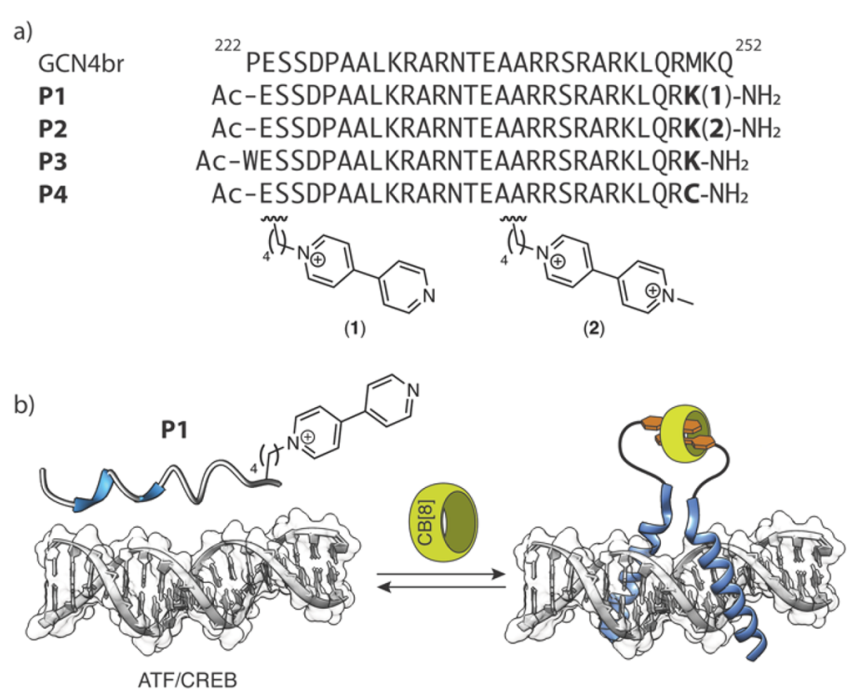

Figure 1. (a) GCN4br sequence, P1 with the 4,4'-bipyripidinium unit (1) conjugated to the C-terminal Lys side chain, P2 with the methylated bipyridinium unit (2), P3 with the free Lys, and P4 in which the Lys has been replaced by Cys to obtain the disulfide dimer $\mathbf{P 4}$. (b) Formation and binding of the homoternary complex $\mathbf{P 1}_{2}: \mathrm{CB}[8]$ with its target dsDNA.
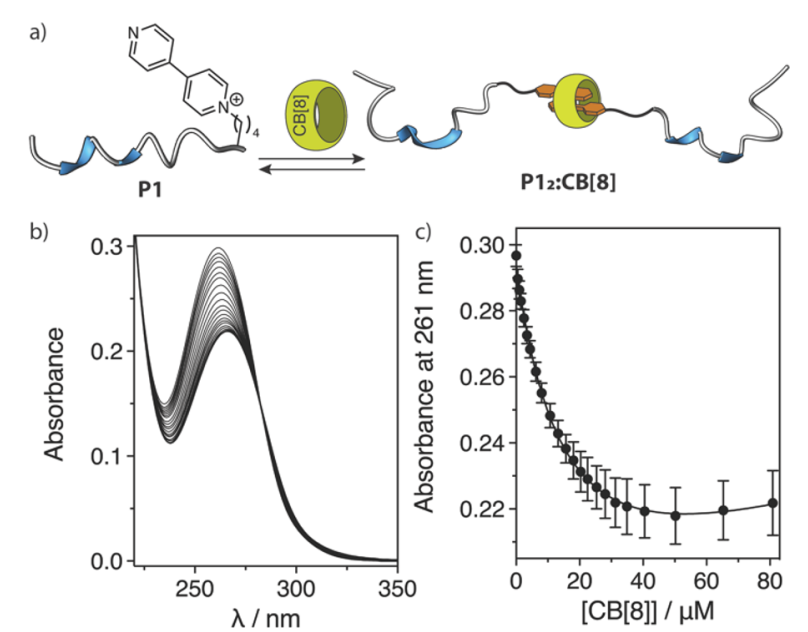

Figure 2. (a) Formation of the homoternary complex $\mathbf{P} \mathbf{1}_{2}: \mathrm{CB}[8]$. (b) UV titration of a $15 \mu \mathrm{M}$ P1 solution in $10 \mathrm{mM}$ phosphate buffer (PB), $\mathrm{pH} 7.0$, in the presence of increasing concentrations of $\mathrm{CB}[8]$. (c) Mean absorbance at $261 \mathrm{~nm}$ and best fit to a sequential 2:1 binding model $\left(\mathbf{P 1}_{2}: \mathrm{CB}[8]\right){ }^{8}$

As the starting point for our design, and based on the crystal structure of the GCN4-ATF/CREB complex, ${ }^{31}$ we used the GCN4br fragment that comprises residues $\mathrm{Glu}^{223}$ to $\mathrm{Arg}^{249}$. This sequence includes all the positive amino acids (Lys and Arg) that are important for the DNA recognition, to which we added an extra Lys residue at the $C$-terminus to attach the $4,4^{\prime}$ bipyridinium scaffold (peptide P1, Figure 1). Taking in consideration previous reports, ${ }^{25,32}$ we expected that P1 should not bind to ATF/CREB as monomer. However, the formation of a supramolecular homodimer with $\mathrm{CB}[8]$ $\left(\mathbf{P 1}_{2}: \mathrm{CB}[8]\right)$ should trigger the recognition of $\mathrm{ATF} / \mathrm{CREB}$.
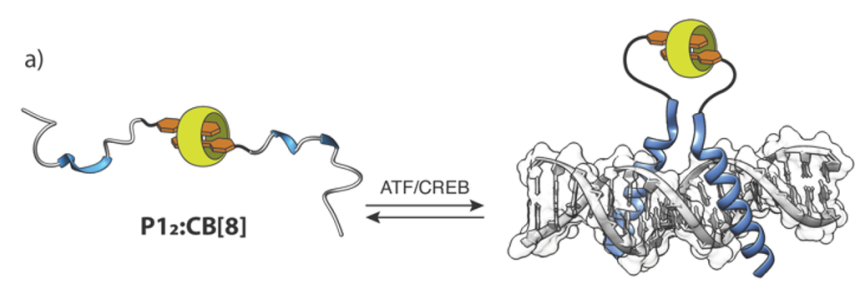

b)

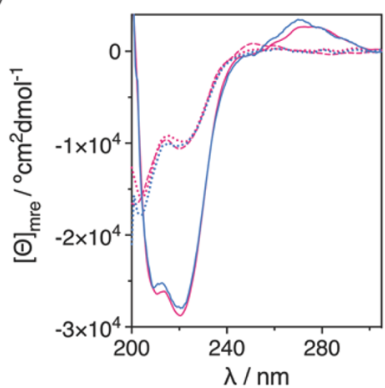

C)

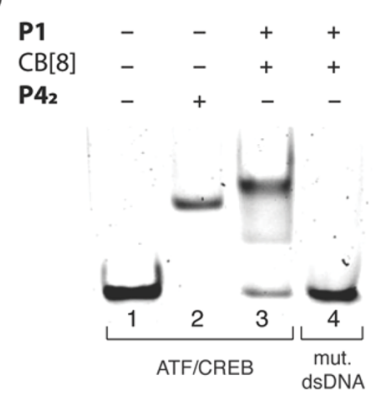

d)

e)
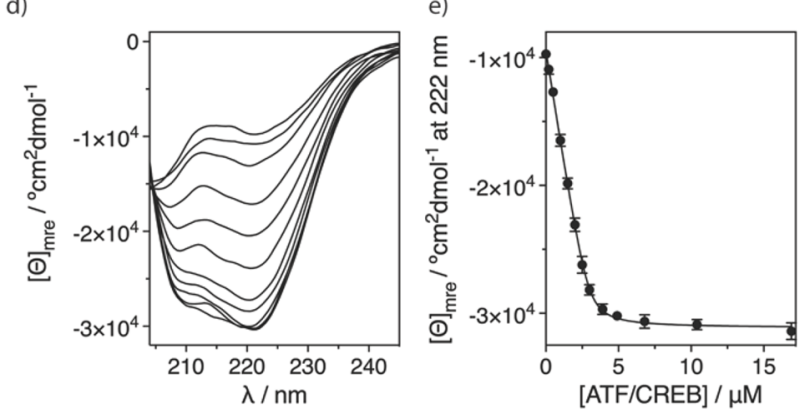

Figure 3. (a) Binding of the supramolecular dimer $\mathbf{P} \mathbf{1}_{2}: \mathrm{CB}[8]$ with ATF/CREB. (b) CD spectra of a $10 \mu \mathrm{M} \mathrm{P1}$ and $18 \mu \mathrm{M} \mathrm{CB}[8]$ mixture (pink dotted line); the same mixture with $5 \mu \mathrm{M}$ ATF/CREB (pink solid line) or $5 \mu \mathrm{M}$ mutated dsDNA (pink dashed line); a $5 \mu \mathrm{M}$ $\mathbf{P 4}_{2}$ solution (blue dotted line) and the same solution with $5 \mu \mathrm{M}$ ATF/CREB (blue solid line). All spectra were recorded at $23.2^{\circ} \mathrm{C}$ in $10 \mathrm{mM} \mathrm{PB}, 100 \mathrm{mM} \mathrm{NaCl}, \mathrm{pH}$ 7.5. (c) DNA binding analysis by electrophoretic mobility shift assay. Lanes 1-3:50 nM ATF/CREB with $500 \mathrm{nM} \mathrm{P4}_{2}$ (lane 2); $1 \mu \mathrm{M}$ P1, $1.8 \mu \mathrm{M} \mathrm{CB}$ [8] (lane 3). Lane 4:50 nM mutated dsDNA, $1 \mu \mathrm{M}$ P1, $1.8 \mu \mathrm{M}$ CB[8]. (d) CD titration of a $10 \mu \mathrm{M} \mathrm{P1}, 18 \mu \mathrm{M}$ CB[8] solution in $10 \mathrm{mM} \mathrm{PB}, 100 \mathrm{mM} \mathrm{NaCl}$, $\mathrm{pH} 7.5$ in the presence of increasing concentrations of ATF/CREB. (e) MRE at $222 \mathrm{~nm}$ and best fit to a $1: 1$ binding model ( $\mathbf{P 1}_{2}: \mathrm{CB}[8]$ :ATF/CREB, considering $\mathbf{P} \mathbf{1}_{2}: \mathrm{CB}[8]$ as a single DNA binding element).

In this case, $\mathrm{CB}[8]$ should form a homoternary complex with the peptide derivative, in which the bipyridinium units are encapsulated in an antiparallel fashion in its hydrophobic cavity $^{23}$ (Figure 1b). Furthermore, $\mathbf{P 1} \mathbf{1}_{2}: \mathrm{CB}[8]$ should be switched by acid-base stimuli, ${ }^{33,34}$ allowing control of its binding to ATF/CREB.

Detailed synthetic protocols are described in the Supporting Information. In short, P1 peptide was synthesized following standard Fmoc/tBu solid-phase peptide synthesis protocols. For the coupling of the 4,4'-bipyridinium unit 1 to the orthogonally deprotected $C$-terminal Lys side chain, we followed our previously reported methodology based on a solid-phase Zincke reaction (Schemes S1 and S2). ${ }^{35}$ In addition to P1, we also synthesized its methylated counterpart P2 and P3, a peptide that lacks the 4,4'-bipyridinium moiety, as negative controls of the DNA binding, and the disulfide dimer of GCN4br, $\mathbf{P 4}_{2}{ }_{2}{ }^{25}$ as positive control (Figure 1a and Schemes S1, S2, S3, and S4). 

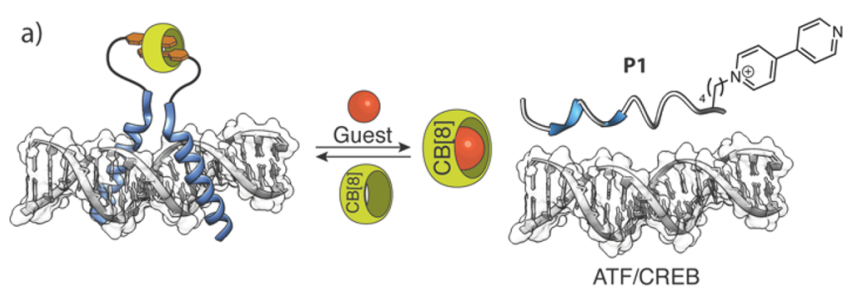

b)

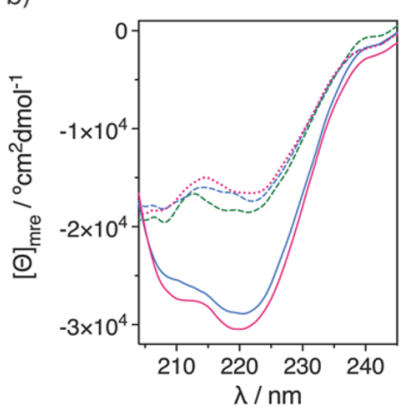

c)

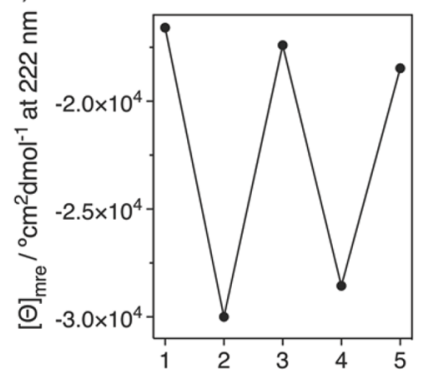

Figure 4. (a) Representation of the switching strategy. (b) ATF/ CREB binding switching experiments by CD. A $10 \mu \mathrm{M}$ P1 and $5 \mu \mathrm{M}$ ATF/CREB mixture in $10 \mathrm{mM} \mathrm{PB}, 100 \mathrm{mM} \mathrm{NaCl}, \mathrm{pH} 7.5$ (pink dotted line) was successively treated at room temperature with $\mathrm{CB}[8]$ and 1-adamantylamine, and the corresponding $\mathrm{CD}$ spectra were recorded after each addition. Starting mixture in the presence of 18 $\mu \mathrm{M} \mathrm{CB}[8]$ (pink solid line); mixture after the addition of 1adamantylamine (2 equiv with respect to $\mathrm{CB}[8]$, blue dashed line); mixture after the addition of a new aliquot of $\mathrm{CB}[8](36 \mu \mathrm{M}$ final concentration, blue solid line); mixture after the addition of 1adamantylamine (other 2 equiv with respect to $\mathrm{CB}[8]$, green dashed line). (c) MRE at $222 \mathrm{~nm}$ for the successive spectra on the left.

With $\mathbf{P 1}$ at hand, we studied its binding to $\mathrm{CB}[8]$ by UV spectroscopy. We observed that the absorption band at 261 $\mathrm{nm}$, corresponding to the bipyridinium moiety, is red-shifted and decreases after the addition of increasing concentrations of $\mathrm{CB}[8]$ (Figure 2b). The UV data were fitted to a sequential 2:1 binding model using DynaFit 4.0 software. ${ }^{36}$ We obtained good quality fittings for a wide range of stepwise dissociation constants that varied significantly. However, as previously observed by Urbach et al. for other $\mathrm{CB}[8]$ homoternary complexes, ${ }^{8}$ the product of each pair of dissociation constants, i.e., the ternary dissociation constants $K_{\mathrm{D}}^{\text {ter }}$, barely varied. Therefore, from the product of the stepwise dissociation constants obtained from the data fitting, we could estimate an apparent $K_{\mathrm{D}}{ }^{\text {ter }} \approx 680 \times 10^{-12} \mathrm{M}^{2}$ for the $\mathbf{P} \mathbf{1}_{2}: \mathrm{CB}[8]$ complex.

To study the DNA binding of the supramolecular dimer $\mathbf{P 1}_{2}$ :CB [8], we first studied the interaction with ATF/CREB by circular dichroism (CD). Since it is well-known that bZip dimers are poorly structured in solution in the absence of their target DNA sequence (therefore, do not show the characteristic CD signature of a continuous $\alpha$-helix), and that bZip monomers cannot bind to their target dsDNA, ${ }^{25,26}$ we first recorded the $\mathrm{CD}$ spectra of a mixture of $\mathbf{P 1}$ and $\mathrm{CB}[8]$ and a mixture of P1 and ATF/CREB (Figures $3 b$ and S1). As expected, none of these mixtures showed the characteristic CD signature of an $\alpha$-helix. However, when we recorded the CD spectrum of a mixture containing P1, CB $[8]$, and ATF/CREB we observed an intense negative $C D$ band with a minimum at $222 \mathrm{~nm}$, characteristic of an $\alpha$-helical structure induced by the interaction of a bZip dimer and its target dsDNA, indicating that $\mathbf{P 1}_{2}$ : $\mathrm{CB}[8]$ retains the DNA binding capabilities of GCN4. In addition, we also wanted to check that this interaction is due to the formation of the 2:1 homoternary complex between the $4,4^{\prime}$-bipyridinium unit and $\mathrm{CB}[8]$, as proposed in Figure $1 b$, and not to a $1: 14,4^{\prime}$-bipyridinium: $\mathrm{CB}[8]$ binary complex or $2: 1$ ternary complexes between $\mathrm{CB}[8]$ and two amine groups from the peptide side chains instead the 4,4'-bipyridinium scaffold. ${ }^{37}$ Interestingly, as shown in Figures S2, S4, S5, and S7, neither the P1:CB[7] binary complex, nor the control peptides P2, which includes the methylated $4,4^{\prime}$-bipyridinium unit that forms $1: 1$ inclusion complexes with $\mathrm{CB}[8],{ }^{19}$ and $\mathrm{P3}$, that does not present the $4,4^{\prime}$-bipyridinium moiety, induced any increase in the negative $\mathrm{CD}$ bands at $222 \mathrm{~nm}$, verifying that they do not interact with ATF/CREB in the presence of $\mathrm{CB}[8]$. Furthermore, we also confirmed that the interaction between $\mathbf{P 1}_{2}: \mathrm{CB}[8]$ and ATF/CREB is sequence-specific by recording the $\mathrm{CD}$ spectrum of a mixture of $\mathrm{P1}, \mathrm{CB}[8]$, and a mutated dsDNA, which did not induce any increase in the negative ellipticity at $222 \mathrm{~nm}$ (Figures $3 \mathrm{~b}$ and S3). As positive control, ${ }^{25}$ we recorded the CD spectrum of the disulfide dimer $\mathbf{P} \mathbf{4}_{2}$ in the presence of ATF/CREB, and it did not exhibit any significant difference with the $\mathrm{CD}$ spectrum of the $\mathbf{P 1}_{2}: \mathrm{CB}[8]: \mathrm{ATF} /$ CREB complex (Figures $3 \mathrm{~b}$ and S6). Moreover, we also confirmed the interaction between the supramolecular dimer $\mathbf{P 1}_{2}: \mathrm{CB}[8]$ and ATF/CREB by electrophoretic mobility shift assays. As expected, we observed a slower migration band for the $\mathbf{P 1}_{2}$ : $\mathrm{CB}[8]$ :ATF/CREB complex that is not observed when $\mathbf{P 1}_{2}: \mathrm{CB}[8]$ is incubated with a mutated dsDNA (Figure $3 \mathrm{c}$, lanes 3 and 4, respectively).

With the purpose of better understanding the interaction between $\mathbf{P 1}_{2}: \mathrm{CB}[8]$ and $\mathrm{ATF} / \mathrm{CREB}$, we performed $\mathrm{CD}$ titrations by adding increasing concentrations of ATF/CREB to a mixture of $\mathbf{P 1}(10 \mu \mathrm{M})$ and $\mathrm{CB}[8](18 \mu \mathrm{M})$. As shown in Figure $3 \mathrm{~d}$, the addition of ATF/CREB induced a continuous increase in the intensity of the negative CD band at $222 \mathrm{~nm}$, characteristic of the $\alpha$-helical structure induced by the DNA binding. The data could be fitted to a 1:1 binding model by considering $\mathbf{P 1}_{2}: \mathrm{CB}[8]$ as a single DNA binding element (Figure 3e, Scheme S6). As a result, we could calculate an apparent dissociation constant, $K_{\mathrm{D}} \approx 75 \pm 16 \mathrm{nM}$, for the formation of the $\mathbf{P 1 _ { 2 }}$ : $\mathrm{CB}[8]$ :ATF/CREB complex, in line with the low nanomolar dissociation constants reported for other GCN4br dimers. ${ }^{38,39}$

Seeing that P1 dimerization and its DNA binding depends on the formation of a supramolecular complex with $\mathrm{CB}[8]$, and taking in consideration that the $4,4^{\prime}$-bipyridinium scaffold in P1 can be protonated yielding acid-base responsive switches, ${ }^{34,40,41} \mathbf{P 1}_{2}: \mathrm{CB}[8]$ has the potential to behave as a supramolecular switch. Therefore, we investigated by $\mathrm{CD}$ if $\mathbf{P 1}_{2}: \mathrm{CB}[8]$ could respond to $\mathrm{pH}$ changes and, thus, control its DNA binding. We registered the $C D$ spectrum of a starting mixture containing P1, $\mathrm{CB}[8]$, and ATF/CREB in $10 \mathrm{mM} \mathrm{PB}$, $\mathrm{NaCl} 100 \mathrm{mM}, \mathrm{pH} \mathrm{7.5}$, and over it we added successive aliquots of $\mathrm{HCl}$ and $\mathrm{NaOH}$. We observed that the intensity of the negative $\mathrm{CD}$ band at $222 \mathrm{~nm}$ decreased significantly after the addition of an aliquot of $\mathrm{HCl}(\mathrm{pH} \approx 4)$ and that the intensity of this negative $\mathrm{CD}$ band was considerably recovered after adjusting the solution back to $\mathrm{pH} \approx 8$ with $\mathrm{NaOH}$, showing that the DNA binding can be reversibly controlled by a $\mathrm{pH}$ change (Figure S8). We also wanted to corroborate that it is possible to reversibly control the formation of $\mathbf{P} \mathbf{1}_{2}$ :CB[8]:ATF/CREB by the addition of competitive guests, such as 1 -adamantylamine and cobaltocenium. Hence, we registered the $\mathrm{CD}$ spectrum of a $\mathrm{P1}, \mathrm{CB}[8]$, and $\mathrm{ATF} / \mathrm{CREB}$ mixture, and again after the addition of successive aliquots of the competitive guests. As shown in Figures 4 and S9, the intensity 
of the negative $\mathrm{CD}$ band at $222 \mathrm{~nm}$ increased and decreased after each addition, demonstrating that the formation of $\mathbf{P 1}_{2}$ : $\mathrm{CB}[8]$ and its DNA binding capability can be reversibly controlled with external stimuli.

In summary, we have presented a new approach to the supramolecular control of peptide assemblies. We have shown that the incorporation of a 4,4'-bipyridinium scaffold at the $C$ terminus of a GCN4br monomer can be used to control its dimerization through the formation of a homoternary supramolecular complex with $\mathrm{CB}[8]$. Moreover, this supramolecular dimer retains the DNA binding properties of the natural transcription factor GCN4. We further demonstrated that the $\mathrm{CB}[8]$-induced dimerization, and thus the DNA binding, can be conveniently disrupted in a reversible fashion by disassembly of the host-guest complex upon the addition of a specific competing guest. Therefore, this strategy offers the possibility of designing new peptide conjugates that can be implemented into complex protein-based networks, and could be reversibly controlled in a straightforward fashion by using the robust and well-established host-guest chemistry of $\mathrm{CB}[8]$.

\section{ASSOCIATED CONTENT}

\section{(s) Supporting Information}

The Supporting Information is available free of charge at https://pubs.acs.org/doi/10.1021/acs.bioconjchem.1c00063.

Peptide synthesis, experimental procedures, analytical data, CD experiments, and DNA binding assays (PDF)

\section{AUTHOR INFORMATION}

\section{Corresponding Authors}

Carlos Peinador - Departamento de Química, Facultade de Ciencias and Centro de Investigacións Científicas Avanzadas (CICA), Universidade da Coruña, 15071 A Coruña, Spain; (ㄱ) orcid.org/0000-0001-5823-6217;

Email: carlos.peinador@udc.es

Elena Pazos - Departamento de Química, Facultade de Ciencias and Centro de Investigacións Científicas Avanzadas (CICA), Universidade da Coruña, 15071 A Coruña, Spain; ㄱorcid.org/0000-0001-9397-2703; Email: elena.pazos@ udc.es

\section{Authors}

Paula Novo - Departamento de Química, Facultade de Ciencias and Centro de Investigacións Científicas Avanzadas (CICA), Universidade da Coruña, 15071 A Coruña, Spain; (1) orcid.org/0000-0001-5777-8487

Marcos D. García - Departamento de Química, Facultade de Ciencias and Centro de Investigacións Científicas Avanzadas (CICA), Universidade da Coruña, 15071 A Coruña, Spain; ○ orcid.org/0000-0002-3189-740X

Complete contact information is available at: https://pubs.acs.org/10.1021/acs.bioconjchem.1c00063

\section{Notes}

The authors declare no competing financial interest.

\section{ACKNOWLEDGMENTS}

We are thankful for the funding received from the European Research Council (ERC) under the European Union's Horizon 2020 research and innovation programme (grant agreement No 851179), the Ministerio de Economía y
Competitividad and Fondo Europeo de Desarrollo Regional (FEDER) (CTQ2016-75629-P), the Agencia Estatal de Investigación and FEDER (CTQ2017-89166-R and PID2019-105272GB-I00) and the Consellería de Educación, Universidade e Formación Profesional, Xunta de Galicia (ED431C 2018/39). P.N thanks the Ministerio de Ciencia, Innovación y Universidades for her PhD fellowship (FPU17/ 04357). E.P. thanks the UDC-Inditex InTalent Programme for her research contract and funding and the Xunta de Galicia for the Oportunius Programme.

\section{ABBREVIATIONS}

$\mathrm{CB}[8]$, cucurbit [8] uril; bZip, basic leucine zipper; GCN4br, GCN4 basic region; Fmoc, fluorenylmethyloxycarbonyl; $t \mathrm{Bu}$, tert-butyl; $\mathrm{CD}$, circular dichroism; $\mathrm{PB}$, phosphate buffer; $K_{\mathrm{D}}$, dissociation constant; MRE, mean residue ellipticity

\section{REFERENCES}

(1) Pawson, T. (2007) Dynamic Control of Signaling by Modular Adaptor Proteins. Curr. Opin. Cell Biol. 19, 112-116.

(2) Reményi, A., Schöler, H. R., and Wilmanns, M. (2004) Combinatorial Control of Gene Expression. Nat. Struct. Mol. Biol. 11, 812-815.

(3) Ueno, M., Murakami, A., Makino, K., and Morii, T. (1993) Arranging Quaternary Structure of Peptides by Cyclodextrin-Guest Inclusion Complex: Sequence-Specific DNA Binding by a Peptide Dimer with Artificial Dimerization Module. J. Am. Chem. Soc. 115, 12575-12576.

(4) Zhang, L., Wu, Y., and Brunsveld, L. A. (2007) Synthetic Supramolecular Construct Modulating Protein Assembly in Cells. Angew. Chem., Int. Ed. 46, 1798-1802.

(5) Nguyen, H. D., Dang, D. T., Van Dongen, J. L. J., and Brunsveld, L. (2010) Protein Dimerization Induced by Supramolecular Interactions with Cucurbit[8]uril. Angew. Chem., Int. Ed. 49, 895-898.

(6) van Dun, S., Ottmann, C., Milroy, L.-G., and Brunsveld, L. (2017) Supramolecular Chemistry Targeting Proteins. J. Am. Chem. Soc. 139, 13960-13968.

(7) Hou, C., Huang, Z., Fang, Y., and Liu, J. (2017) Construction of Protein Assemblies by Host-Guest Interactions with Cucurbiturils. Org. Biomol. Chem. 15, 4272-4281.

(8) Heitmann, L. M., Taylor, A. B., Hart, P. J., and Urbach, A. R. (2006) Sequence-Specific Recognition and Cooperative Dimerization of N-Terminal Aromatic Peptides in Aqueous Solution by a Synthetic Host. J. Am. Chem. Soc. 128, 12574-12581. Later reports have demonstrated that the formation of the $\mathrm{CB}[8]:(\mathrm{FGG})_{2}$ complex is non-cooperative: Cavatorta, E., Jonkheijm, P., and Huskens, J. (2017) Assessment of Cooperativity in Ternary Peptide-Cucurbit[8]uril Complexes. Chem. - Eur. J. 23, 4046.

(9) Dang, D. T., Nguyen, H. D., Merkx, M., and Brunsveld, L. (2013) Supramolecular Control of Enzyme Activity through Cucurbit[8]uril-Mediated Dimerization. Angew. Chem., Int. Ed. 52, 2915-2919.

(10) de Vink, P. J., Briels, J. M., Schrader, T., Milroy, L. G., Brunsveld, L., and Ottmann, C. (2017) A Binary Bivalent Supramolecular Assembly Platform Based on Cucurbit[8]uril and Dimeric Adapter Protein 14-3-3. Angew. Chem., Int. Ed. 56, 8998-9002.

(11) Sonzini, S., Ryan, S. T. J., and Scherman, O. A. (2013) Supramolecular Dimerisation of Middle-Chain Phe Pentapeptides via $\mathrm{CB}[8]$ Host-Guest Homoternary Complex Formation. Chem. Commun. 49, 8779-8781.

(12) Sankaran, S., Kiren, M. C., and Jonkheijm, P. (2015) Incorporating Bacteria as a Living Component in Supramolecular Self-Assembled Monolayers through Dynamic Nanoscale Interactions. ACS Nano 9, 3579-3586.

(13) Jeon, W. S., Kim, E., Ko, Y. H., Hwang, I., Lee, J. W., Kim, S.-Y., Kim, H.-J., and Kim, K. (2005) Molecular Loop Lock: A Redox- 
Driven Molecular Machine Based on a Host-Stabilized ChargeTransfer Complex. Angew. Chem., Int. Ed. 44, 87-91.

(14) An, Q., Brinkmann, J., Huskens, J., Krabbenborg, S., De Boer, J., and Jonkheijm, P. (2012) A Supramolecular System for the Electrochemically Controlled Release of Cells. Angew. Chem., Int. Ed. 51, 12233-12237.

(15) Bosmans, R. P. G., Hendriksen, W. E., Verheijden, M., Eelkema, R., Jonkheijm, P., van Esch, J. H., and Brunsveld, L. (2015) Supramolecular Protein Immobilization on Lipid Bilayers. Chem. Eur. J. 21, 18466-18473.

(16) Samanta, S. K., Moncelet, D., Briken, V., and Isaacs, L. (2016) Metal-Organic Polyhedron Capped with Cucurbit[8]uril Delivers Doxorubicin to Cancer Cells. J. Am. Chem. Soc. 138, 14488-14496.

(17) Cavatorta, E., Voskuhl, J., Wasserberg, D., Brinkmann, J., Huskens, J., and Jonkheijm, P. (2017) Targeting Protein-Loaded CB[8]-Mediated Supramolecular Nanocarriers to Cells. RSC Adv. 7, 54341-54346.

(18) Zhang, Y. M., Liu, J. H., Yu, Q., Wen, X., and Liu, Y. (2019) Targeted Polypeptide-Microtubule Aggregation with Cucurbit[8]uril for Enhanced Cell Apoptosis. Angew. Chem., Int. Ed. 58, 1055310557.

(19) Pazos, E., Novo, P., Peinador, C., Kaifer, A. E., and García, M. D. (2019) Cucurbit[8]uril (CB[8])-Based Supramolecular Switches. Angew. Chem., Int. Ed. 58, 403-416.

(20) Blanco-Gómez, A., Cortón, P., Barravecchia, L., Neira, I., Pazos, E., Peinador, C., and García, M. D. (2020) Controlled Binding of Organic Guests by Stimuli-Responsive Macrocycles. Chem. Soc. Rev. 49, 3834-3862.

(21) Pigliacelli, C., Sánchez-Fernández, R., García, M. D., Peinador, C., and Pazos, E. (2020) Self-Assembled Peptide-Inorganic Nanoparticle Superstructures: From Component Design to Applications. Chem. Commun. 56, 8000-8014.

(22) Neira, I., Blanco-Gómez, A., Quintela, J. M., Garciá, M. D., and Peinador, C. (2020) Dissecting the "Blue Box": Self-Assembly Strategies for the Construction of Multipurpose Polycationic Cyclophanes. Acc. Chem. Res. 53, 2336-2346.

(23) Vincil, G. A., and Urbach, A. R. (2008) Effects of the Number and Placement of Positive Charges on Viologen-Cucurbit[n]uril Interactions. Supramol. Chem. 20, 681-687.

(24) Ellenberger, T. E., Brandl, C. J., Struhl, K., and Harrison, S. C. (1992) The GCN4 Basic Region Leucine Zipper Binds DNA as a Dimer of Uninterrupted $\alpha$ Helices: Crystal Structure of the ProteinDNA Complex. Cell 71, 1223-1237.

(25) Talanian, R. V., Mcknight, C. J., and Kim, P. S. (1990) Sequence-Specific DNA Binding by a Short Peptide Dimer. Science 249, 769-771.

(26) Cuenoud, B., and Schepartz, A. (1993) Altered Specificity of DNA-Binding Proteins. Science 259, 510-513.

(27) Caamaño, A. M., Vázquez, M. E., Martínez-Costas, J., Castedo, L., and Mascareñas, J. L. (2000) A Light-Modulated SequenceSpecific DNA-Binding Peptide. Angew. Chem., Int. Ed. 39, 3104-3107. (28) Mosquera, J., Jiménez-Balsa, A., Dodero, V. I., Vázquez, M. E., and Mascareñas, J. L. (2013) Stimuli-Responsive Selection of Target DNA Sequences by Synthetic bZip Peptides. Nat. Commun. 4, 1874.

(29) Bullen, G. A., Tucker, J. H. R., and Peacock, A. F. A. (2015) Exploiting Anthracene Photodimerization within Peptides: Light Induced Sequence-Selective DNA Binding. Chem. Commun. 51, $8130-8133$.

(30) Boga, S., Bouzada, D., García Peña, D., Vázquez López, M., and Vázquez, M. E. (2018) Sequence-Specific DNA Recognition with Designed Peptides. Eur. J. Org. Chem. 2018, 249-261.

(31) Keller, W., König, P., and Richmond, T. J. (1995) Crystal Structure of a bZip/DNA Complex at 2.2 A: Determinants of DNA Specific Recognition. J. Mol. Biol. 254, 657-667.

(32) Talanian, R. V., McKnight, C. J., Rutkowski, R., and Kim, P. S. (1992) Minimum Length of a Sequence-Specific DNA Binding Peptide. Biochemistry 31, 6871-6875.
(33) Zhang, Z.-J., Zhang, Y.-M., and Liu, Y. (2011) Controlled Molecular Self-Assembly Behaviors between Cucurbituril and Bispyridinium Derivatives. J. Org. Chem. 76, 4682-4685.

(34) Xu, Y., Wang, X., and Ma, X. (2017) Reversible End-to-End Assembly and Disassembly of Gold Nanorods Based on pHResponsive Host-Guest Interaction. Dyes Pigm. 145, 385-390.

(35) Cortón, P., Novo, P., López-Sobrado, V., García, M. D., Peinador, C., and Pazos, E. (2020) Solid-Phase Zincke Reaction for the Synthesis of Peptide-4,4'-Bipyridinium Conjugates. Synthesis 52, 537-543.

(36) Kuzmič, P. (1996) Program DYNAFIT for the Analysis of Enzyme Kinetic Data: Application to HIV Proteinase. Anal. Biochem. 237, 260-273.

(37) Barrow, S. J., Kasera, S., Rowland, M. J., del Barrio, J., and Scherman, O. A. (2015) Cucurbituril-Based Molecular Recognition. Chem. Rev. 115, 12320-12406.

(38) Cuenoud, B., and Schepartz, A. (1993) Design of a MetallobZip Protein That Discriminates between CRE and AP1 Target Sites: Selection against AP1. Proc. Natl. Acad. Sci. U. S. A. 90, 1154-1159.

(39) Jiménez-Balsa, A., Pazos, E., Martínez-Albardonedo, B., Mascareñas, J. L., and Vázquez, M. E. (2012) Temporary Electrostatic Impairment of DNA Recognition: Light-Driven DNA Binding of Peptide Dimers. Angew. Chem., Int. Ed. 51, 8825-8829.

(40) Yang, H., Chen, H., and Tan, Y. (2013) Cucurbit[8]uril Inducing Supramolecular Hydrogels by Adjusting pH. RSC Adv. 3, 3031-3037.

(41) Li, J., Yu, Y., Luo, L., Li, Y., Wang, P., Cao, L., and Wu, B. (2016) Square [5]Molecular Necklace Formed from Cucurbit[8] uril and Carbazole Derivative. Tetrahedron Lett. 57, 2306-2310. 